\title{
MICROFRANCHISING MICROLEARNING CENTERS: A SUSTAINABLE MODEL FOR EXPANDING THE RIGHT TO EDUCATION IN DEVELOPING COUNTRIES?
}

\author{
Tiffany Zenith Ivins \\ Director of International Programs \\ Center for Open Sustainable Learning
}

\begin{abstract}
While availability of information and access to it enables education in developing countries, information alone does not secure transmission of knowledge-especially to remote learners in low-tech, infrastructure-poor communities. For this reason, $21^{\text {st }}$ century distance education tools require innovative mechanisms for accessing the hardest-to-reach learners. This paper explores an ethnographic case study from Nepal as a means for illuminating the possibility for expanding the right to education in developing countries through an innovative approach: the microfranchising of microlearning centers.
\end{abstract}

\section{KEYWORDS}

Youth, Development, ICT4D, YMRC, Technology, Nepal, South Asia, Social Entrepreneurs

\section{DEVELOPING WORLD CONTEXT}

Nearly one-half the world's population lives in acute poverty. Illiteracy is associated with extreme poverty and other dilemmas that impede well-being. Despite this, one-fifth of the world's population is still denied the right of literacy. Worldwide, women are less literate than men with lowest literacy rates in developing countries, particularly Africa and Asia [1]. Eliminating various forms of poverty (economic, social, physical, spiritual) is directly linked to improving opportunities for education in the developing world.

The right to education is one of the most important rights proclaimed by the Universal Declaration of Human Rights, because education is considered by the Declaration to be not only a right in itself but also a means of promoting peace and respect for human rights and fundamental freedoms generally [2]. Effectively disseminating education in developing countries requires the removal of obstacles in the way of the right to education. This is most likely to be achieved through a holistic approach with concerted focus on sustainable and context-sensitive programming conducted by locals for locals with particular regard to localized content collection and dissemination [3].

\section{ICT AND LITERACY}

As the economic gap between rich and poor continues to widen, another gap is emerging between the elite with access to information technology and the poor without it. But, could ICTs make a difference to development through distance education [4]? In what ways may high quality learning tools be tailored for the needs of rural people in formats suitable for lower-literate needs? Through what mechanisms may 
communities with low-infrastructure be primed to access such tools? The World Bank and other international development groups propose that ICTs must contribute to education goals and poverty reduction strategies in the $21^{\text {st }}$ century. With globalization, the information revolution, and increasing demands for a highly skilled work force, it is clear that nations must accord high priority to building the capacity to effectively utilize technology in education [5].

What mechanisms or existing models may facilitate this educational revolution in order to afford the right to education to more individuals across the globe? What are the potential benefits of open source and open content in order to provide rural and disenfranchised groups with access to knowledge that is broadly available but still inaccessible to those who need it most? In what formats should this be delivered, and in what manner could individuals be primed to utilize this resource? What training and infrastructures must be provided in order for people to benefit on the ground?

Participants in literacy classes rarely enroll because they wish to read "for reading's sake;" the majority of participants view literacy as a vehicle to learning knowledge useful for everyday life and to initialize social change in areas of health, income-generation, and agricultural/community development. As Freire aptly concluded, "The fundamental question about education is, 'What is to know?" [6]. For most people, especially those in developing countries, 'to know' is 'to do.' Thus, distance education in developing countries must be directly linked to action.

\section{MICROLEARNING CENTERS}

In contrast to macroeducation (or a 'one-size-fits-all' design for rural curricula, learning structures, or pedagogies), microeducation offers an alternative concept that educational options may be created and packaged in a tailored manner according to the needs, experiences, and goals of individual students. In parallel to microcredit, which offers a small source of capital to an individual with a tailored business plan, microeducation would offer a small source of start-up learning materials to an individual with a tailored education plan. In this vein, distance education would provide an opportunity for rural learners to access information and learning tools strategically suited to their personal goals with as narrow/broad scope as desired. Microlearning Centers are community learning centers focused on microeducation as it facilitates access to educational information for low-literate and illiterate peoples in remote communities.

\section{DISTANCE EDUCATION AND OER}

UNESCO Director-General, Koichiro Matsuura, declared that, "To remain human and livable, knowledge societies will have to be societies of shared knowledge” [7]. This statement directly correlates with the objective of distance education as pertaining to the nascent Open Educational Resources (OER) movement - the sharing of knowledge worldwide. The term Open Educational Resources (OER) was adopted at a 2002 UNESCO meeting to refer to open provision of educational resources, enabled by ICTs, for consultation, use and adaptation by a community of users for non-commercial purposes [8].

With the advent of the Open Educational Resource (OER) movement, distance education has been bolstered through availability of OpenCourseWare (OCW) and communal, non-proprietary information repositories. OER is particularly relevant to distance education in the $21^{\text {st }}$ century since connectivity to the Internet is growing; low cost computers and enhanced mobile devices enable leapfrogging of infrastructural setbacks; and, the body of open content is proliferating.

Although quality information is more readily available than ever before, many question whether the 
technologies of distance education, including OER, act as an enabler or as a barrier to achieve the universal right to education? Susan D'Antoni stated in her paper for the 2007 Open Education Conference, "If knowledge is to be shared as OER, new approaches will be needed.” The OER movement expressly aims to increase access to knowledge and educational opportunities worldwide through sharing educational content, but how does one reach those on the ground? What delivery mechanisms may allow distance education to really "go the distance" in order to expand the right to education for all?

While OER is substantially impacting the resource bank for distance education, strategic vehicle for delivering such tools is still needed for disseminating critical content to learners who seek it, particularly those in rural areas. In order for OER to enhance the expansion of the right to education in developing countries, certain priorities must be addressed: awareness raising, capacity building, quality assurance and sustainability [9]. Change agents are necessary at the grassroots level in order for distance education to fulfill the right to education through a process of accessing, localizing, and disseminating information.

\section{MICROFRANCHISING OVERVIEW}

Microfranchising, an adaptation of microcredit, is an increasingly successful approach for helping budding entrepreneurs in developing countries to adopt a proven enterprise model and to cut back on teething problems faced by amateur business owners. Different from franchising, microfranchising not only creates an income, it also focuses on delivery of critical social services in far-flung areas where infrastructure is weak and resources are limited [10]. Could microfranchising of microlearning centers (e.g. one-stop-shop education centers based on a scalable, replicable design) offer a sustainable model for increasing the right to education in developing countries via distance education opportunities? A deeper look at microfranchise models may illuminate possibilities.

The Scojo Foundation in El Salvador aims to create jobs while increasing access to affordable reading glasses. Most people will need vision correction at some point in their lives, but access to eye doctors and glasses is non-existent in most rural areas. For $\$ 120$, Scojo microfranchisees purchase a vision kit which includes: a backpack filled with glasses, an eye-examination chart, and tee-shirt with the Scojo brand. Locally-trained villagers become trusted microfranchisees who then make the rounds in rural communities to provide optical check-ups and match people with much-needed glasses; beyond providing this social service, each microfranchisee earns a 50\% margin for each pair of glasses sold [11].

Some other organizations with existing models of microfranchising include: Fan Milk (bicycle-riding microfranchisees improve protein and calcium levels while selling milk products in Ghana); Cellular City (entrepreneurs provide access to information and communication through sales of second-hand cell phones in the Philippines); and FINCA (rural healthcare suppliers visit remote communities equipped with reasonably priced anti-malaria drugs and locally-made bed nets treated with insecticide).

Although microfranchising is still a new phenomenon, three salient benefits are job creation, specific training, and effective delivery. The medium of microfranchising has been termed "The Next Big Thing" in a recent Economic Times article because of its potential for facilitating linkages to value chains, continued training, ongoing mentoring, scalability, and business creativity [12]. Educationalists like the concept because of its innovative means for transferring knowledge; business people like it because it generates profits while delivering services to the base of the economic pyramid. 


\section{MICROFRANCHISING MICROLEARNING CENTERS}

Microfranchising of microlearning centers is a viable model for implementing the right to education by addressing several key questions of distance education: How do we replicate success to scale? How do we empower the informal sector? What initial and ongoing training is necessary and for whom do we provide it? How do we design effective tools tailored for the needs of clients? This model of microfranchising may serve as a catalyst for the privatization and scaling up of UNESCO's proven model for Community Learning Centers (CLC) which offer integrated distance learning opportunities in developing countries. Refining this model will prepare rural people with strategies to access open educational resources (e.g. OCW), to utilize and tailor open source software, and to develop new learning materials customized for the needs of remote communities. In this way, right to education may be achieved through enhanced knowledge, market access, and expanded freedoms.

\section{CASE STUDY: YOUTH-MANAGED RESOURCE CENTERS IN NEPAL}

As a member of the Center for Open Sustainable Learning (COSL), I conducted research in Nepal from April to June 2007. My goal was to identify pilot sites which hold the promise for development of a microfranchising model based on a successful microlearning center focused on sustainable delivery of community-oriented educational services. The model identified was the Youth-Managed Resource Center (YMRC) initiative, and the specific site highlighted in this case study is the Sankhu Rural Information Technology Center, managed by Ramita Shrestha, a 24 year-old volunteer.

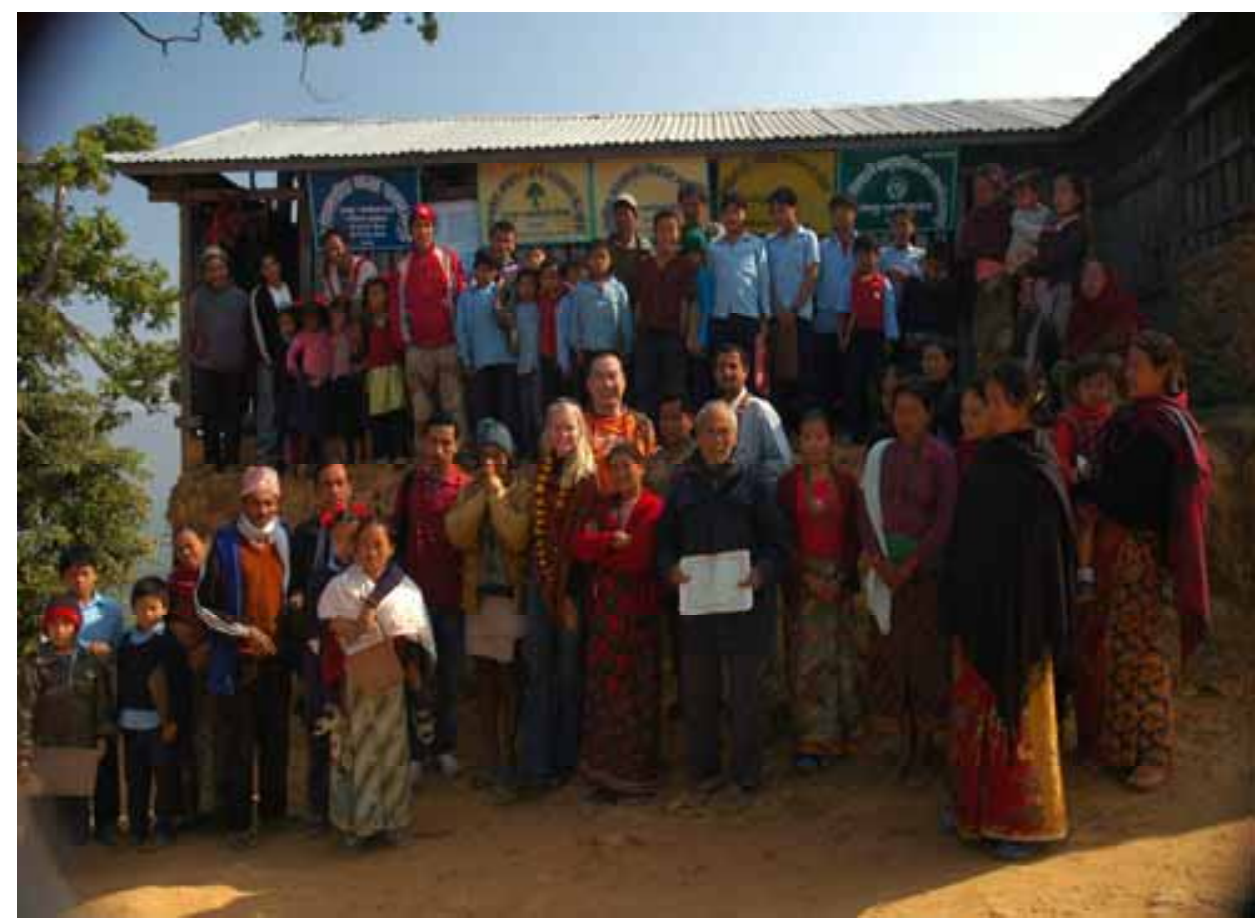

Image 1. Youth-Managed Resource Center: Maskichaap Village, Gorkha District, Nepal

Youth-Managed Resource Centers (YMRC) are Himalayan learning centers which advance integrated educational and entrepreneurial opportunities through technologies tailored for remote communities. Here, youth volunteers facilitate rural villagers who wish to access critical information and disseminate 
customized educational tools (health, agricultural, economic content) in far-flung mountain villages.

The goal of the YMRC is to amplify rural educational and entrepreneurial opportunities through improved access to technology and utilization of relevant information from digital libraries, online content, and OER. Due to the rugged Himalayan terrain of these communities, rural people suffer from delayed dissemination of information; the YMRC responds to this need by facilitating access to critical information, thereby increasing opportunities for untouchables and ethnic groups to generate income through community entrepreneurship.

Here's how it works: Rural youth between the ages of 12 and 22 (sometimes called the "Village Ambassadors"), trek into the YMRC (for some, a three-hour journey one-way) to collect information pertinent to their lives and to the lives of those in their villages. After surfing an offline local intranet (with a cache of useful resources uploaded flash drive with current content collected online in Kathmandu), these mobile youth then trek home to share their new knowledge with women's groups, agricultural cooperatives, and literacy classes. In this way, the culture of technology amplifies education and development opportunities by bridging information gaps where information and technology are limited.

The YMRC provides training and facilitation of community action projects in remote villages, particularly emphasizing the role of youth as community mobilizers who empower others from their disadvantaged and minority groups. Recognizing the opportunities afforded through distance education technologies, this rural microlearning center functions as a catalyst for community development and social change.

The YMRC in Sankhu received start-up funding for two computers, a printer, and a one-year salary for a facilitator. Since its inception in 2004, community awareness of YMRC's services has grown and demand has escalated proportionately. Because of this, the YMRC is able to charge a minimal fee for training, mentoring, and support for information-seeking. Through a strict savings plan, the center has managed to get 4 more computers and a 4-in-1 machine (printer, scanner, fax, and copier).

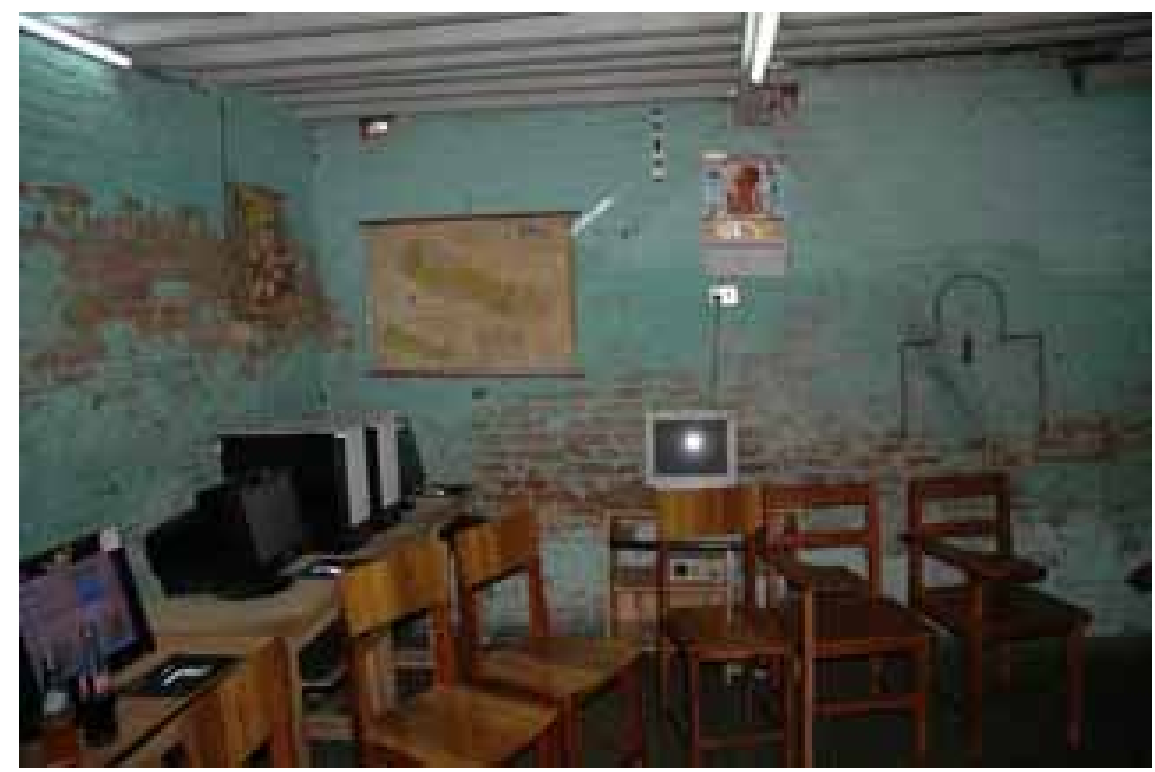

Image 2. A spare room in rural Sankhu is equipped with computers and an intranet of useful content for training other villagers in distance education. 
The entrepreneurial, charismatic spirit of the Sankhu Center's Manager (Ramita) and the unique socialcomponent which the center emphasizes to youth trainees, allows this YMRC to attract more clients than the local for-profit cyber-cafes. To date, the YMRC has survived without foreign funding and has been operating independently for three years. In addition, this center provides previously unavailable educational and entrepreneurial opportunities to indigenous and disenfranchised peoples.

Besides offering training related to ICTs and modern technologies, the YMRC sponsors a "Community Youth Club" (CYC) that provides a weekly forum for youth. The CYC is a platform whereby youth have a voice, explore current events, and engage in training related to development-oriented action projects for their remote villages, particularly emphasizing the role of youth as community mobilizers who empower others from their disadvantaged and minority groups.

The YMRC attempts to answer some difficult questions regarding the right to education through distance education. After the "Village Ambassadors" (youth volunteers) are trained in strategic technologies at the YMRC, they then facilitate access to information for other members of their remote villages by trekking home with print and audio versions of content collected online. In this new twist of distance education, each individual becomes an agent to eradicate their own personal ignorance as well as to address the educational poverty of their family and community members.

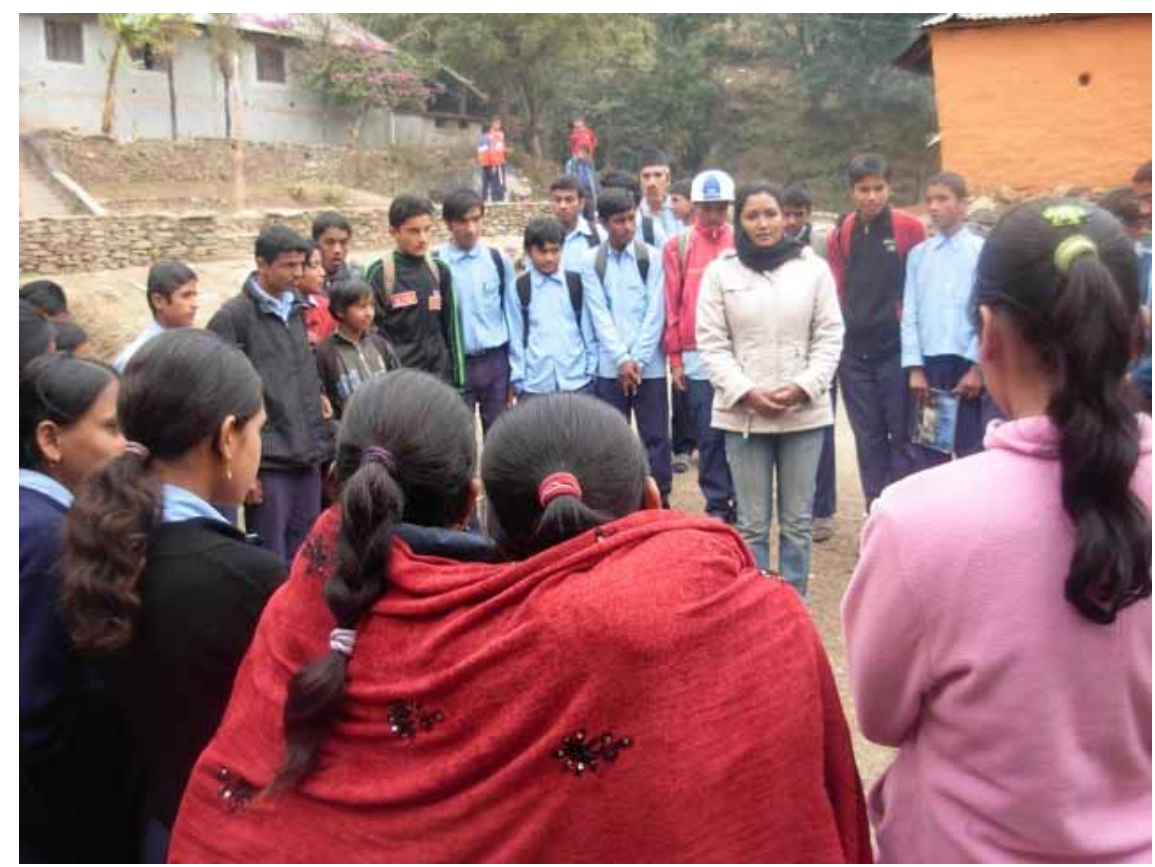

Image 3. The Community Youth Club (CYC) advocates for the right to education for all. Youth mobilize their villages to utilize the YMRC to access critical information.

This model developed by the Village Ambassadors "involves both the processes that allow freedom of actions and decision, and the actual opportunities that people have, given their personal and social circumstances” [13]. In this vein, the YMRC provides an opportunity for rural learners to access information and learning tools strategically suited to their personal goals with as narrow or broad a scope as desired. This allows participants to progress at different levels, according to individual needs, context, and previous preparation. It also is a system which cultivates youth leadership skills. 


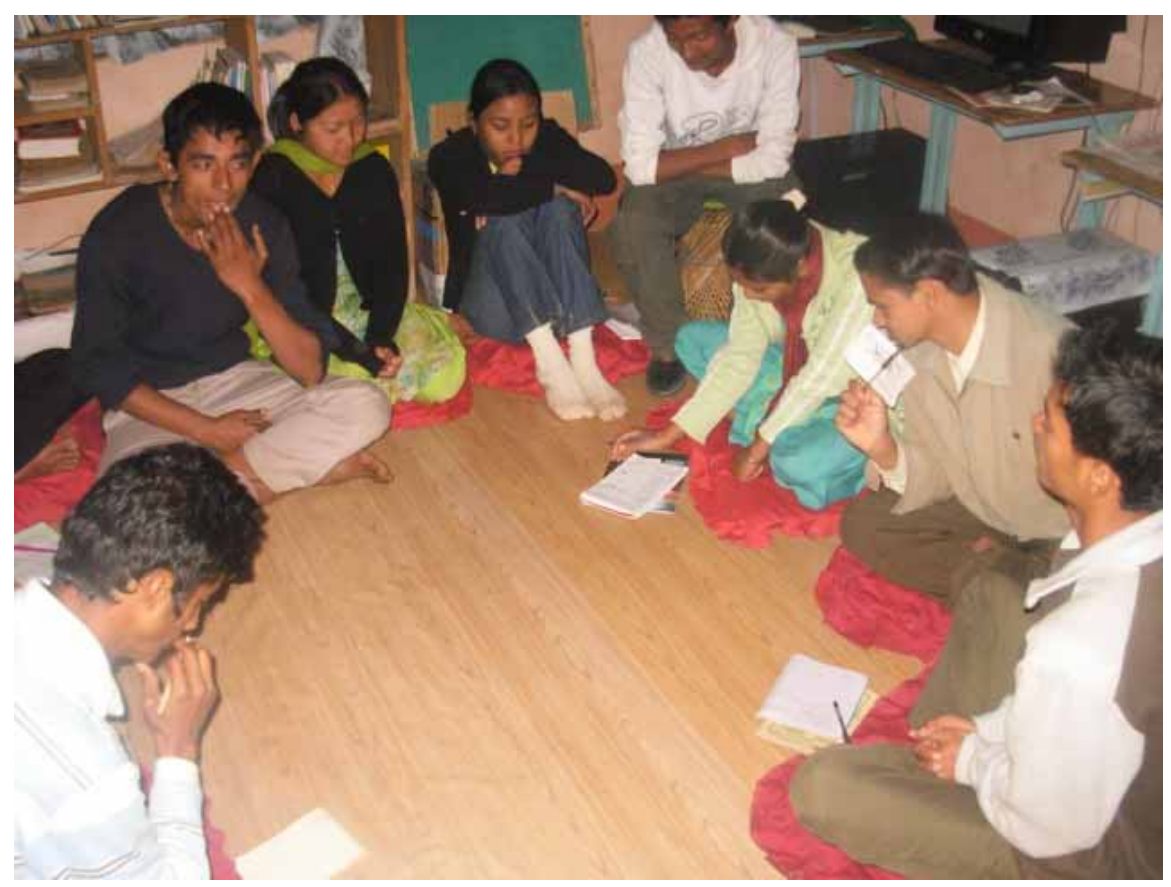

Image 4. Youth managers discuss strategic plan for their center in order to enable outreach of services to more rural beneficiaries.

The YMRC appears to offer an opportunity to microfranchise integrated learning centers in rural communities. As an outcrop of micro-enterprise, where small entrepreneurs start small businesses with small loans, microfranchising can allow for small entrepreneurs to build from successful business plans of other rural entrepreneurs. Appropriate technologies and approaches will need to be tailored uniquely according to the clientele of each microfranchisee; however, greater odds for success are ensured if one builds upon successful strategies of other YMRC sites.

Microfranchising microlearning centers would allow for optimal educational and entrepreneurial empowerment for rural groups. Connecting individuals through intranets, and communities through the Internet, this strategic approach may likely facilitate broader information exchange and realization of the right to education for eager beneficiaries in even more communities.

The YMRC is proposed as a viable model for implementing the right to education because it addresses several key questions of distance education: How do we replicate success to scale? How do we empower the informal sector? What initial and ongoing training is necessary and for whom do we provide it? How do we design effective tools tailored for the needs of clients? In effect, each "village ambassador," is also a change agent, mobilizing their respective women's groups, agricultural cooperatives, and literacy class participants.

The YMRC model of microfranchising may also serve as a catalyst for the privatization and scaling up of UNESCO's proven model for Community Learning Centers (CLC) that offer integrated distance learning opportunities in developing countries. Refining this model may potentially prepare rural people with strategies to access open educational resources (e.g. OCW), to utilize and tailor open source software, and to develop new learning materials customized for the needs of remote communities. In this way, the right to education may be achieved through the YMRC by enhancing knowledge, increasing market access, and expanding other freedoms. 


\section{MOVING FORWARD}

The microfranchising of microlearning centers offers an opportunity for small entrepreneurs to build from successful business plans of a successful educational center that has built a name for itself by providing critical information and friendly service support while generating a profit. If implemented, rookie village entrepreneurs with an interest to improve education in developing countries may strategically build upon a respectable name, a community-oriented reputation, and a proven business model. For a nominal fee, a franchise license may be purchased, with an accompanying toolkit composed of the proven strategies for initializing and maintaining their microlearning center (YMRC) endeavor.

At that point, venture capital from a pro-poor investor (or "angel") may be given for start-up resources (technologies, training, awareness raising); however, this money will be paid back in a micro-loan manner as well as through training and monitoring services whereby the veteran microfranchisees mentor the novice microfranchisees. Herein is practical application of Prahalad's proposition that widespread development and poverty alleviation will only occur if "we stop thinking of the poor as victims ... and start recognizing them as resilient, creative entrepreneurs and value-conscious consumers” [14].

\section{SUSTAINABILITY}

Because of the high global demand for education and the paucity of educational service providers in developing countries, distance education is a great entrepreneurial venture. However, because of extreme poverty, very few for-profit (and pro-poor) educational ventures have been explored in remote developing countries. In order to be effective, the refining of an effective educational model (which could then be taken to scale) would still need some start-up costs covered. But, what about funding? Could this be done without support from agencies? Perhaps through an "angel" for each new site? In tandem with the "Village Ambassadors" concept, several models of social entrepreneurship may also be applied and should be explored further through participatory dialogue sessions held in grassroots communities.

In these ways, microfranchising has great promise for distance education in developing countries; the model allows social entrepreneurs to invest in poor countries, allowing them to 'do well and do good' at the same time. Start-up funding and training may be given pursuant to approval of a locally-developed strategic plan. After that, microlearning centers may then begin to generate enough profits to pay back their original loan. In turn, other centers may receive those funds and training so the cycle may continue.

\section{CONCLUSION}

Education is hampered and poverty is exacerbated in rural developing countries because of a paucity of reading materials and limited access to information. This challenge may be addressed through the subsidizing and supporting of rural entrepreneurs to establish integrated educational facilities (e.g. a nexus of context-sensitive training, customized hardware and software, connectivity, and regular technical support) in order to initiate change, generate profits, and improve rural well-being.

In summary, expanding the right of education in developing countries may be bolstered through replication of successful microfranchising models for distance education in rural microlearning centers. These centers, staffed by local change agents, trained in appropriate technologies and equipped with a toolkit for localizing and disseminating OER, will sustain the distance education movement through locally owned centers which generate profits through training, mentoring, and other services in order to be sustainable. 


\section{REFERENCES}

1. UNESCO. Literacy for Life: EFA Global Monitoring Report. Paris: UNESCO, 2006.

2. UNESCO. Universal Declaration of Human Rights. Paris: UNESCO, 1948.

3. Tomasevski, K. Removing Obstacles in the Way of the Right to Education. Right to Education Primers, Number 1. Gothenburg, Sweden: Swedish International Development Association, 2005.

4. ID21. Missing the Connection? Using ICTs in Education. Insights Education: Development Research Quarterly. Brighton: University of Sussex, 2003.

5. World Bank. ICTs and Education in the Developing World. Washington DC: World Bank, 2007.

6. Freire, P. Education for Critical Consciousness. New York: The Continuum Publishing Company, 1973.

7. UNESCO. Towards Knowledge Societies: UNESCO World Report. Paris: UNESCO, 2005.

8. UNESCO. Forum on the Impact of Open CourseWare for Higher Education in Developing Countries: Final Report. Paris: UNESCO, 2002.

9. D'Antoni, S. Open Educational Resources-The Way Forward: Deliberations of an International Community of Interest. Paris: UNESCO International Institute for Educational Planning (IIEP), 2007.

10. Fairbourne, J. Microfranchising: A New Tool for Creating Economic Self-Reliance. Economic Self Reliance Review. Provo: Center for Economic Self-Reliance, Brigham Young University, 2006.

11. Fairbourne, J. Microfranchising. Marriott School Alumni Magazine. Provo: Center for Economic Self-Reliance, Brigham Young University, 2007.

12. Aiyar, S. "Microfranchising: The Next Big Thing.” Economic Times: 9 October 2007.

13. Sen, A. Development as Freedom. Oxford: Oxford University Press, 1998.

14. Prahalad, C. K. The Fortune at the Bottom of the Pyramid: Eradicating Poverty through Profits. New Jersey: Wharton School Publishing, 2005.

\section{OTHER RESOURCES}

1. BYU. What is MicroFranchising? Provo: Center for Economic Self-Reliance, Brigham Young University, 2006. http://marriottschool.byu.edu/selfreliance/microfranchise/about.cfm.

2. Curtis, L. Literacy for Social Change. New York: New Readers Press, 1990.

3. Fernandez, B. Literacy in Francophone Countries, Situations and Concepts. Background paper for Education For All Global Monitoring Report, 2006: 2005.

4. Fransman, J. Understanding Literacy. Background paper for Education For All Global Monitoring Report, 2006: 2005.

\section{ABOUT THE AUTHOR}

Tiffany Zenith Ivins (MSC, BA) is a PhD candidate at Utah State University where she is also the Director of International Programs for the Center for Open and Sustainable Learning (COSL). Tiffany holds a Masters degree in International and Comparative Education from the University of Oxford and a Bachelor's Degree from Brigham Young University. She has worked with several international NGOs: World Education, ProLiteracy Worldwide, Laubach Literacy International, and Community Development Network (an NGO she helped start while a student in Oxford). Tiffany has consulted for literacy programs in South Africa, Sudan, Kenya, Nepal, China and the Philippines. She is particularly interested in youth, gender, and participatory ICT for rural educational development. 